\title{
Clinical features of systemic lupus erythematosus in Sri Lankan patients: results from a lupus clinic
}

\author{
P Galapatthy', A N Wazeel', S Nanayakkara ${ }^{3}$ and R Sheriff \\ (Index words: Visceral involvement, alopecia, pregnancy, outcomes).
}

\begin{abstract}
Objectives To find the common clinical features, pattern of visceral involvement, treatment received and outcome in patients diagnosed as having systemic lupus erythematosus (SLE) on American Rheumatological Association (ARA) criteria.
\end{abstract}

Setting Clinic for patients referred or admitted to the University Medical Unit, National Hospital of Sri Lanka, Colombo, with diagnosed or suspected SLE.

Design and methods A prospective descriptive study. Clinical features of patients collected at time of registration in the clinic were maintained in a database. Patients were followed up prospectively and changes recorded. Data were analysed after 3 years of follow up.

Results Of the 111 patients registered during this period, $96(86 \%)$ were clinically diagnosed as having SLE. Of these, 77 patients (80\%) satisfied ARA criteria for diagnosis of SLE. 72 were females (93\%). The mean age of patients who satisfied the ARA criteria was 32 years (range 11 to 58), and the mean duration of disease 7 years (range 1 to 15). The commonest presentation was with mucocutaneous features (98\%) and alopecia in $87 \%$. Systemic features were found in $92 \%$ of patients. 67 (87\%) of patients had visceral involvement with $60(78 \%)$ having it at time of diagnosis. $53(69 \%)$ had renal, $42(54 \%)$ haematological, 33 (42\%) neurological, 12 (16\%) cardiac and 8 patients pulmonary involvement. Five patients died during the 3-year follow up and 2 developed chronic renal failure. Three patients underwent successful pregnancy after diagnosis of SLE.

Conclusions Our study confirmed the wide variability of clinical features seen in SLE. Alopecia and visceral involvement were common in Sri Lankan patients.

\section{Introduction}

SLE is a multi-system autoimmune disease where the incidence, prevalence and the clinical features are known to vary with factors such as race, gender, ethnicity, age and country of birth $(1,2)$. The disease occurs world-wide, and is most commonly found among women of child-bearing age (2).

Publications from different centres have shown marked variation in the clinical features of SLE among different races (2), and several reports have noted a difference in the clinical features of SLE between Asians and other subjects $(3,4,5,6)$.

There are no published data on clinical features of patients with SLE in Sri Lanka. We have analysed the clinical features of SLE diagnosed on ARA criteria in patients attending our lupus clinic.

\section{Methods}

We did a descriptive analysis of data in SLE patients prospectively in the University Lupus Research clinic which was started in 1996 with the objective of providing better care and follow up for patients with SLE. Detailed data on clinical features, investigations, complications and treatment of these patients were entered in a database. The ARA classification criteria were used for the diagnosis of SLE. Those not satisfying the diagnostic criteria were further investigated for other autoimmune diseases and followed up.

\section{Results}

The results are summarised in Tables 1 to 7. The demographic data of patients are shown in Table 1. Of the 77 patients satisfying the ARA criteria for diagnosis, $72(93 \%)$ were female. There were $80 \%$ Sinhalese, $13 \%$ Moor and 5\% Tamils. There were patients from all 9 provinces of Sri Lanka: $44 \%$ were from Western province, $19 \%$ from Southern and $13 \%$ from North-Western.

\section{Table 1. Demographic data of patients}

\begin{tabular}{ll} 
Number registered in the clinic & 111 \\
Patients with 'clinical' diagnosis of SLE & $96(86 \%)$ \\
Patients who satisfy ARA criteria & $77(80 \%)$, 72 female \\
Mean age of SLE patients & 32 years (range 11 to 58) \\
Mean duration of SLE & 7 years (range 1 to 15) \\
\hline
\end{tabular}

The commonest presentation was with mucocutaneous features (98\%) which included alopecia, malar rash, discoid rash, photosensivity, oral ulcers, vasculitis and Raynaud's phenomenon (Table 2). A majority (92\%) also had systemic features such as fever, loss of appetite and weight loss, and $85 \%$ had musculoskeletal features such as arthralgia or arthritis: 67 patients $(87 \%)$ had visceral involvement, and $49(80 \%)$ had visceral involvement at diagnosis.

There were 53 patients (69\%) with renal involvement. The renal histology was available in the majority, and was classified according to the WHO classification of lupus nephritis on renal biopsy appearance (Table 3). Table 3 gives the details of clinical manifestations.

'Senior Registrar in Medicine and Lecturer, Department of Pharmacology, ${ }^{2}$ Registrar in Medicine, ${ }^{3}$ Senior Lecturer, Department of Medicine, 'Professor of Medicine, Faculty of Medicine, University of Colombo. (Revised version accepted 16 September 2000). 
Table 2. Systemic, musculoskeletal and mucocutaneous features in patients with SLE
Feature

Systemic disturbances

Fever

Loss of appetite

Loss of weight

Musculoskeletal

Arthalgia

Arthritis

Mucocutaneous

Alopecia

Malar rash

Discoid rash

Photosensitivity

Oral ulcers

Vasculitis

Raynaud's phenomenon
Number (\%)

71 (92\%)

$65(84 \%)$

$50(64 \%)$

42 (55\%)

$66(85 \%)$

$53(68 \%)$

$49(64 \%)$

75 (98\%)

$67(87 \%)$

$44(57 \%)$

$7(9 \%)$

26 (34\%)

$42(55 \%)$

$16(20 \%)$

$16(20 \%)$
Table 3. Visceral involvement in patients with SLE

$\begin{array}{lc}\text { Visceral involvement } & \text { Number (\%) } \\ \text { Total } & 67(87 \%) \\ \text { Renal } & 53(69 \%) \\ \text { Class I lupus nephritis } & 1 \\ \text { Class II lupus nephritis } & 8(15 \%) \\ \text { Class III lupus nephritis } & 9(17 \%) \\ \text { Class IV lupus nephritis } & 17(33 \%) \\ \text { Class V lupus nephritis } & 4(8 \%) \\ \text { Haematological } & 42(54 \%) \\ \text { Anaemia } & 39(92 \%) \\ \text { Haemolytic anaemia } & 8 \\ \text { Thrombocytopaenia } & 11 \\ \text { Leucopaenia } & 7 \\ \text { Neurological } & 33(42 \%) \\ \text { Psychosis } & 11 \\ \text { Seizures } & 13 \\ \text { Chorea } & 5 \\ \text { CVA } & 4 \\ \text { Neuropathy } & 4 \\ \text { Cerebellar involvement } & 4 \\ \text { Cervical myelopathy } & 2 \\ \text { Cardiac } & 12(16 \%) \\ \text { Pericardial effusion } & 6 \\ \text { Valve involvement } & 5 \\ \text { Coronary artery disease } & 5 \\ \text { Pulmonary } & 2 \\ \text { Pleural effusion } & 2 \\ \text { Restrictive lung disease } & \\ \text { Pulmonary hypertension } & \\ \text { (* CVA = Cerebrovascular accident) } & \\ & \\ & \end{array}$

Table 4. Specific findings of investigations in 77 SLE patients

\begin{tabular}{lcrc} 
Investigation & $\begin{array}{c}\text { Positive } \\
(\%)\end{array}$ & $\begin{array}{c}\text { Negative } \\
(\%)\end{array}$ & $\begin{array}{c}\text { Not available } \\
(\%)\end{array}$ \\
ANA & $68(88 \%)$ & $4(5 \%)$ & $5(6 \%)$ \\
Anti-DsDNA & $19(25 \%)$ & $37(48 \%)$ & $21(27 \%)$ \\
LEcells & $8(10 \%)$ & $10(13 \%)$ & $59(77 \%)$ \\
VDRL & 0 & $7(9 \%)$ & $70(91 \%)$ \\
Lupus anticoagulant & $2(3 \%)$ & $11(14 \%)$ & $64(83 \%)$ \\
\hline
\end{tabular}

The specific findings at investigations are given in Table 4. A majority of patients ( $>90 \%$ ) needed treatment with immunosuppressive drugs (Table 5).

Five patients died during follow up (Table 6) giving an incidence of death of 7\% for a mean duration of illness of 7 years. Three patients became pregnant, and where pregnancy progressed beyond the first trimester, delivered live healthy babies. Two patients had a complicated puerperium, but recovered fully.

Table 5. Immunosuppressive drugs used in SLE patients

\begin{tabular}{lr} 
Prednisolone & $73(95 \%)$ \\
Azathioprine & $57(74 \%)$ \\
Cyclophosphamide (oral, IV) & $26(34 \%)$ \\
Cyclophosphamide (IV) & 8 (10\%) \\
Methylprednisolone & 5 (6\%) \\
Dexamethasone & 11 (14\%) \\
\hline
\end{tabular}

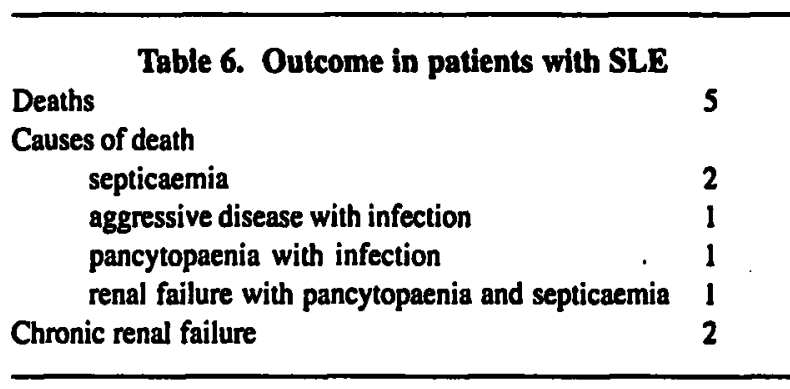

\section{Discussion}

The diverse clinical features in SLE may result from the variable influence of genetic, immunological, hormonal and environmental factors (7), with epidemiological studies from different parts of the world giving varying prevalence rates for common features of SLE $(7,8)$.

In the absence of a single screening test with a high specificity and sensitivity, the diagnosis of SLE is made on the basis of the ARA (now the American College of Rheumatology) criteria for the diagnosis of SLE (9). The presence of any 4 of these 11 criteria either concurrently or sequentially at any time of the disease enables the diagnosis of SLE with $98 \%$ specificity and $97 \%$ sensitivity (9).

Although the ARA criteria for lupus are used for clinical diagnosis, they were developed for classifying patients in clinical trials and epidemiological studies (10). Some characteristic visceral involvements such as chorea, peripheral neuropathy, and restrictive lung disease, which were seen in our patients, are not part of the ARA criteria. Consequently, some of our patients did not fulfill the ARA diagnostic criteria. The late development of some clinical features included in the ARA criteria, several months or years after initial illness, is another reason why all SLE patients do not fulfill ARA criteria initially. However, we used the ARA criteria to include patients for our study, as in other studies which have analysed the clinical features of SLE $(11,12,13,14)$. Some patients who were referred to our clinic did not have SLE, and 26 had a different autoimmune disease. 
The SLE features seen in our study compared with other series $(11,12,13,14)$ are given in Table 7 . This comparison shows a higher prevalence of alopecia $(88 \%)$ in our patients, and the lowest prevalence for malar rash (66\%). There were no striking differences noted in other clinical manifestations. The female preponderance shown in all previous studies is confirmed in our study.

The visceral involvement seen in $87 \%$ patients is in keeping with the observation of high prevalence of internal organ disease in Asians (6). The majority of our patients with renal involvement had focal proliferative or diffuse proliferative nephritis (WHO classes III and IV) which are considered as severe lupus nephritis. Neurological involvement was also noted in a number of patients and chorea was more prevalent in this study population compared to others $(17,18)$.

Atherosclerosis is emerging as a significant cause of death and illness in patients with long standing SLE (19). The mortality rate from coronary artery disease in patients with SLE is estimated to be 9 times that predicted on population based rates (20). The reasons for accelerated atherosclerosis in SLE include the high prevalence of risk factors such as hypertension, hyperlipidaemia and obesity, and treatments such as corticosteroids (9).

The treatment of patients in our clinic depended on the severity of the disease and visceral involvement. Patients with severe disease and with life-threatening major organ involvement received induction therapy with methylprednisolone, dexamethasone and cyclophosphamide as recommended in accepted treatment protocols $(21,22)$.

Recent studies have documented substantial improvement in the survival of patients with SLE $(23,24,25)$ with 5 year survival rates of over $90 \%$ and 10 -year survival rates of over $80 \%(24,25,26)$. Thus our mortality figure of $6 \%$ during 3-year follow up for a mean duration of illness of 7 years, is comparable to other series. The leading causes of death in patients with lupus are infectious complications and clinical manifestations directly related to lupus itself $(24,25)$. In many patients infections develop in the setting of active lupus under aggressive treatment: thus it is often difficult to identify a single cause of death (27). The successful outcome of pregnancies noted in our patients is also in keeping with results from recent studies (28).

This study of clinical features of SLE in Sri Lankan patients confirms the wide variability of clinical features in the disease and its ethnic variations. We observed alopecia and visceral involvement to be more common in Sri Lankan patients. SLE remains a serious disease with significant morbidity and mortality.

\section{Acknowledgements}

We acknowledge the co-operation of all the patients in our lupus clinic.

Table 7. Cumulative percentage incidence of some SLE features in Sri Lankan and data from other large studies

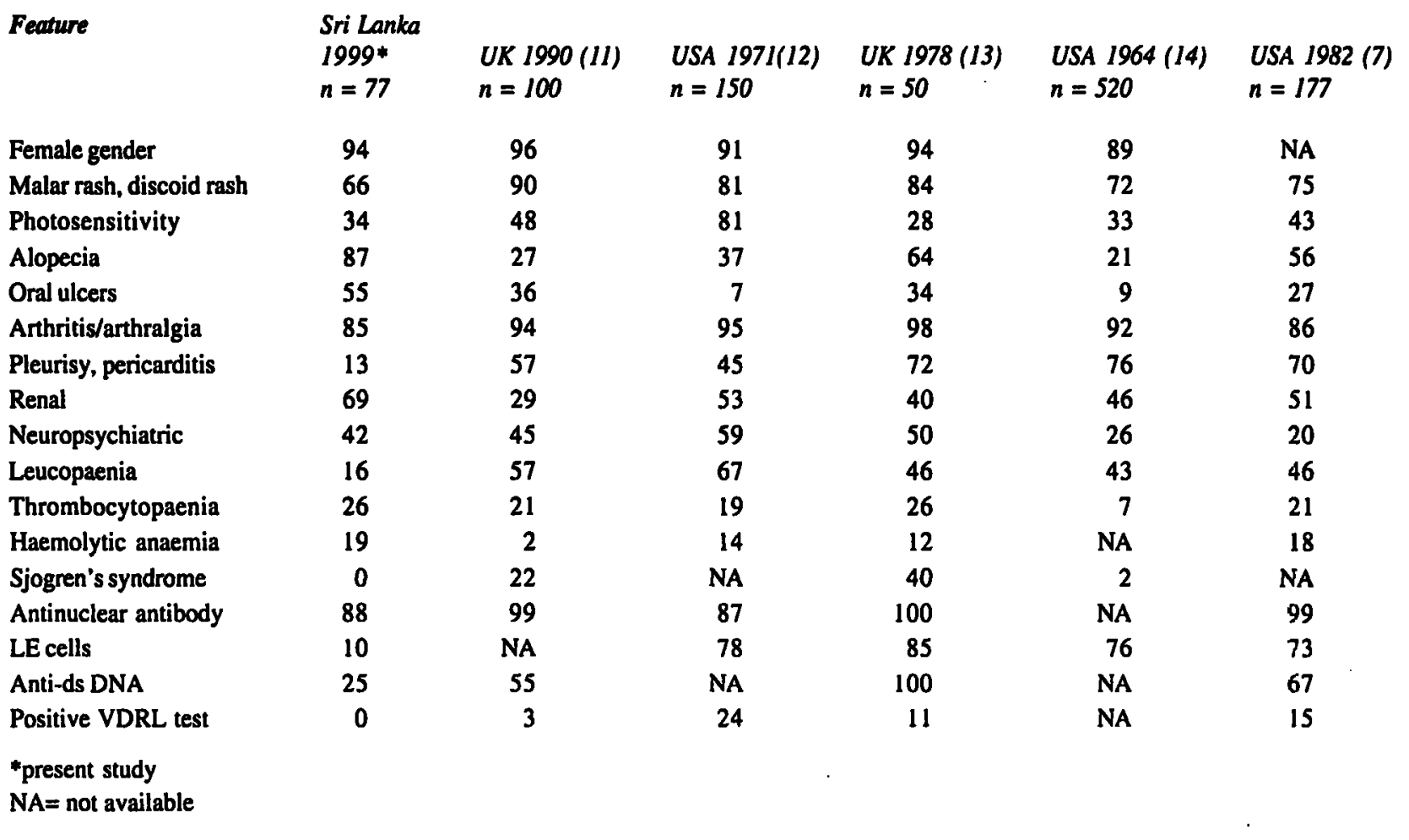




\section{References}

1. Johnson AE, Gorden C, Palmer RG, Bacon PA. The prevalence and incidence of systemic lupus erythematosus. Relationship to ethnicity and country of birth. Arthritis and Rheumatism 1995; 38: $551-8$.

2. Snaith ML, Isenburg DA. Systemic lupus erythematosus and related disorders. In: Weatherall DJ, Ledigham JGG, Warrel DA, eds. Oxford Textbook of Medicine. $3^{\text {td }}$ edition. 1996; Oxford: Oxford University Press, 3017-27.

3. Feehally J, Burden AC, Mayberry JF, Probert CSJ, Roshan M, Samantha AK, Woods SKL. Disease variations in Asians in Leicester. Quarterly Journal of Medicine 1993; 86: 263-9.

4. Malavia AN, Misra R, Banerjee S, Kumar A, et al. Systemic lupus erythematosus in North Indian Asians. A prospective analysis of clinical and immunological features. Rheumatology International 1986; 6: 97-101.

5. Pande I, Malavia AN, Sekharan NG, Kailash S, Uppal SS, Kumar A. SLE in Indian men: analysis of the clinical and laboratory features with review of literature. Lupus 1994; 3: 181-6.

6. Samantha A, Feehally J, Roy S, Nichol FE, Sheldon PJ, Walls J. High prevalence of systemic disease and mortality an Asian subjects with systemic lupus erythematosus. Annals of Rheumatic Diseases 1991; 50: 490-2.

7. Tan EM, Cohen ES, Fries JF, Masi AT, McShane DJ, Rothfield NF, et al. The 1982 revised criteria of the classification of systemic lupus erythematosus. Arthritis and Rheumatism 1982; 25: 1271-7.

8. Nived OLA, Sturfelt G, Wollheim F. Systemic lupus erythematosus in an adult population in southern Sweden: incidence prevalence and validity of ARA revised classification criteria. British Joumal of Rheumatology 1985; 24: 147-54.

9. Boumpas DT, Austin H, Fessler BJ. Systemic lupus erythematosus: emerging concepts Part 1: Renal neuropsychiatric, cardivascular, pulmonary and haematologic disease. Annals of Internal Medicine 1995; 122: 940-50.

10. Hay EM, Snaith ML. Systemic lupus erythematosus and lupus like syndromes. British Medical Journal 1995; 310: 1257-61.

11. Worrel JG, Snaith ML, Batchelor JR, Isenberg DA. SLE: a Rheumatological view. Analysis of clinical features, serology, and immunogenetics in 100 SLE patients during long term follow up. Quarterly Journal of Medicine 1990; 74: 319-30.

12. Estes D. Christian CL. The natural history of systemic lupus erythematosus by prospective analysis. Medicine 1971; 50: 85-95.

13. Grigor R, Edmonds J, Lewkonia R, Bresnihan B; Hughes GRV Systemic lupus erythematosus. A prospectice analysis. Annals of Rheumatic Diseases 1978; 37; 121-8.

14. Dubois EL, Tuffenelli DL. Clinical manifestations of systemic lupus erythematosus. Journal of the American Medical Association. 1964; 190: 104-11.

15. Golbus J, Mc Cune WJ. Lupus nephritis. Classification, prognosis, immunpathogenesis and treatment. Rheumatic Disease Clinics of North America 1994; 20: 213-42.

16. Esdaile JM, Federgreens W, Quintal H, Suissa S, Heysleu JP, Kashgarian M. Predictors of one year outcome in lupus nephritis: The importance of renal biopsy. Quarterly Joumal of Medicine 1991; 81: 907-18.

17. West SG. Neuropsychiatric lupus. Rheumatic Disease Clinics of Nonh America 1994; 20: 129-58.

18. Lim L, Ron MA, Ormerold IEC, et al. Psychiatric and neurological manifestations in systemic lupus erythematosus. Quarterly Journal of Medicine 1988; 66: 27-38.

19. Sturfelt G, Eskillson J, Nived O. Cardiovascular disease in systemic lupus erythematosus: A study of 75 patients from a defined population. Medicine (Baltimore) 1992; 71: 216-23.

20. Johnson H, Nived O, Sturfelt G. Outcome in systemic lupus erythematosus: a prospective study of patients from a defined population. Medicine (Baltimore) 1989; 68: 141-50.

21. Systemic lupus erythematosus. Drug and Therapeutics Bulletin 1996; 34: 20-2.

22. Bansel VK, Beto JA, et al. Treatment of lupus nephritis: a meta analysis of clinical trials. American Joumal of Kidney Disease 1997; 29: 193-9.

23. Boumpas DT, Austin H, Fessler BJ. Systemic lupus erythematosus: emerging concepts Part 2: Dermatologic and joint disease, antiphospholipid antibody syndrome, pregnancy and hormonal therapy, morbidity, mortality, and pathogenesis. Annals of Internal Medicine 1995; 123: 42-53.

24. Swaark AJ, Nossent J, Bronswelt W, et al. Systemic lupus erythematosus I. Outcome and survival. Dutch experience with 110 patients studied prospectively. Annals of Rheumatic Diseases 1989; 48: 447-54.

25. Pistiner M, Wallace DJ, Nessim S, et al. Lupus erythematosus in the 1980s: a survey of $\mathbf{5 7 0}$ patients. Seminars in Arthritis and Rheumatism 1991; 21: 55-64.

26. Rubin LA, Urowitz MB, Gladman DD. Mortality in systemic lupus erythematosus: the bimodial pattern revisited. Quarterly Journal of Medicine 1985; 216: 87-98.

27. Cohen MG, Li EK. Mortality in systemic lupus erythematosus active disease is the most important factor. Australian and New Zealand Joumal of Medicine 1992; 22: 5-8.

28. Carmonia S, Font J, Cervera R, et al. Obstetrical outcome of pregnancy in patients with systemic lupus erythematosus. A study of 60 cases. European Journal of Obstetrics and Gynaecology and Reproductive Biology 1999; 83: 137-42. 